\title{
Improved production of Humira antibody in the genetically engineered Escherichia coli SHuffle, by co-expression of human PDI-GPx7 fusions
}

\author{
Marine Lénon $^{1,2} \cdot \mathrm{Na} \mathrm{Ke}^{1} \cdot$ Cecily Szady ${ }^{1} \cdot$ Hassan Sakhtah $^{1,3} \cdot$ Guoping Ren $^{1} \cdot$ Bruno Manta $^{1,4} \cdot$ Bryce Causey $^{1}$. \\ Mehmet Berkmen ${ }^{1}$ (iD
}

Received: 3 July 2020 / Revised: 11 September 2020 / Accepted: 18 September 2020 / Published online: 30 September 2020

(C) The Author(s) 2020

\begin{abstract}
Microbial production of antibodies offers the promise of cheap, fast, and efficient production of antibodies at an industrial scale. Limiting this capacity in prokaryotes is the absence of the post-translational machinery, present in dedicated antibody producing eukaryotic cell lines, such as B cells. There has been few and limited success in producing full-length, correctly folded, and assembled IgG in the cytoplasm of prokaryotic cell lines. One such success was achieved by utilizing the genetically engineered Escherichia coli strain SHuffle with an oxidative cytoplasm. Due to the genetic disruption of reductive pathways, SHuffle cells are under constant oxidative stress, including increased levels of hydrogen peroxide $\left(\mathrm{H}_{2} \mathrm{O}_{2}\right)$. The oxidizing capacity of $\mathrm{H}_{2} \mathrm{O}_{2}$ was linked to improved disulfide bond formation, by expressing a fusion of two endoplasmic reticulum-resident proteins, the thiol peroxidase GPx7 and the protein disulfide isomerase, PDI. In concert, these proteins mediate disulfide transfer from $\mathrm{H}_{2} \mathrm{O}_{2}$ to target proteins via PDI-Gpx7 fusions. The potential of this new strain was tested with Humira, a blockbuster antibody usually produced in eukaryotic cells. Expression results demonstrate that the new engineered SHuffle strain (SHuffle2) could produce Humira IgG four-fold better than the parental strain, both in shake-flask and in high-density fermentation. These preliminary studies guide the field in genetically engineering eukaryotic redox pathways in prokaryotes for the production of complex macromolecules.
\end{abstract}

\section{Key points}

- A eukaryotic redox pathway was engineered into the E. coli strain SHuffle in order to improve the yield of the blockbuster antibody Humira.

- The best peroxidase-PDI fusion was selected using bioinformatics and in vivo studies.

- Improved yields of Humira were demonstrated at shake-flask and high-density fermenters.

Electronic supplementary material The online version of this article (https://doi.org/10.1007/s00253-020-10920-5) contains supplementary material, which is available to authorized users.

Mehmet Berkmen

berkmen@neb.com

New England Biolabs, 240 County Road, Ipswich, MA 01938, USA

2 Present address: Department of Microbiology, Stress Adaptation and Metabolism in Enterobacteria Unit, UMR CNRS 2001, Institut Pasteur, 25-28 Rue du Dr Roux, 75015 Paris, France

3 Present address: Boston Institute of Biotechnology, LLC., Upstream Process Development, 225 Turnpike Road, Southborough, MA 01772, USA

4 Present address: Facultad de Medicina, Departamento de Bioquímica and Centro de Investigaciones Biomédicas, Universidad de la República, CP 11800 Montevideo, Uruguay
Keywords SHuffle - GPx7 - PDI - Redox engineering · Humira production $\cdot$ Disulfide bond $\cdot$ E. coli

\section{Introduction}

Antibody-based technologies is an expanding field in biotech and pharmaceutical industries with a myriad of applied tools in biological research. Microbial production of therapeutic and engineering of diagnostic antibody derivatives offers great potential for cheap, fast production of novel antibody designs. Limiting this potential is the correct folding and assembly of the tetrameric antibody ( $\mathrm{IgG})$. The production of an $\mathrm{IgG}$ macromolecule demands the assembly of two light and two heavy chains to be stoichiometrically associated, along with the requirement for post-translational modifications of proline 
isomerization and glycosylation and for 8 intra and 2 interchain disulfide bonds (Feige et al. 2009). Consequently, the production of $\mathrm{IgG}$ is not a trivial problem especially in the context of a prokaryotic expression system.

In the model prokaryotic expression organism Escherichia coli, expression of antibodies and derivatives has been limited to the periplasmic compartment (Simmons et al. 2002) mainly due to its native disulfide bond-forming machinery (Manta et al. 2019). Yet, periplasmic expression requires extensive optimization of conditions (Baumgarten et al. 2018) to avoid secretion blockage (Schlegel et al. 2012) and optimization of targeting signal peptides (Karyolaimos et al. 2019; Mirzadeh et al. 2020). More importantly, the periplasm lacks ATP (Alvarez et al. 2017) and thus is devoid of ATP-dependent chaperone systems, making the cytoplasm the preferred compartment for protein expression.

The cytoplasm of E. coli contains two disulfide bondreducing pathways, an unsuitable compartment for the production of disulfide-bonded proteins. The problem of the reductive compartment of the cytoplasm was circumvented with the redox engineering of the cytoplasmic redox pathway of E. coli, resulting in the protein expression strain, SHuffle (Lobstein et al. 2012) or by co-expressing a eukaryotic oxidase pathway (Gaciarz et al. 2017). SHuffle cells have diminished disulfide bond reducing power due to the deletion of thioredoxin reductase $(\operatorname{tr} x B)$ and glutathione reductase (gor) along with a suppressor mutation in the peroxidase AhpC (Ritz et al. 2001).

Redox engineered E. coli SHuffle cells have been previously demonstrated to be an attractive platform for the expression of various antibody formats, such as full-length IgG (Reddy et al. 2018; Robinson et al. 2015), Fab' fragments (Abe et al. 2014; Mori et al. 2018; Yusakul et al. 2018), scFv chains (Ahmadzadeh et al. 2020; Liu et al. 2019; Vermeulen et al. 2018) and VHH domains (Eliseev et al. 2018; Ta et al. 2015; Zarschler et al. 2013). Although SHuffle cells lack the eukaryotic glycosylation machinery, by engineering mutations in the $\mathrm{Fc}$ region of antibodies, the requirement for glycosylation for efficient binding of the IgG to its cognate receptor was bypassed (Robinson et al. 2015). Furthermore, unlike mammalian or yeast cells, expression of antibodies in SHuffle cells permits the efficient labelling of antibodies with heavy isotopes for structural studies (Reddy et al. 2018). A microbial platform for the design, selection, and production of antibodies in a rapid manner, especially in response to an emerging infection is therefore essential. Not surprisingly, many new methods and strains have been developed to increase the microbial capacity of recombinant antibody production (Gupta and Shukla 2017; Spadiut et al. 2014; Zhang et al. 2020). In this study, the genetic tools available to E. coli were utilized to engineer synthetic eukaryotic redox pathway and evaluate its effect on the production of the most profitable and widely used therapeutic antibody Humira (adalimumab) against human tumor necrosis factor alpha $(\mathrm{TNF} \alpha)$, used as a blocker to treat rheumatoid arthritis (Scheinfeld 2003).

SHuffle cells are under constant oxidative stress, presumably due to loss of peroxidase activity of $\mathrm{AhpC}$, resulting in the accumulation of hydrogen peroxide $\left(\mathrm{H}_{2} \mathrm{O}_{2}\right)$ (Reuter et al. 2019). The accumulation of $\mathrm{H}_{2} \mathrm{O}_{2}$ is known to cause oxidative stress (Hong et al. 2019) and may not only damage the proteome of SHuffle cells but also perturb recombinant protein expression. This insight allowed us to postulate linking the oxidizing capacity of $\mathrm{H}_{2} \mathrm{O}_{2}$ to disulfide bond formation using the endoplasmic resident eukaryotic glutathione peroxidase-7 (GPx7) and the enzyme responsible for oxidative folding, the Protein Disulfide bond Isomerase (PDI).

The peroxidase superfamily present in all domains of life can be divided into 8 subgroups (Toppo et al. 2008). GPx7 is an endoplasmic reticulum (ER)-resident peroxidase that contributes to oxidative protein folding by reducing $\mathrm{H}_{2} \mathrm{O}_{2}$ and donating its disulfide bond to PDI (Wang et al. 2014) (Nguyen et al. 2011). Oxidized PDI participates in oxidative folding of proteins both in vivo and in vitro (Wang et al. 2014).

Engineering of a eukaryotic PDI-GPx7 coupled redox pathway is therefore an attractive option, as the components may not need to interact with a prokaryotic system. In this study, an attempt was made to genetically engineer a eukaryotic redox pathway that naturally resides in ER, to express and function in the cytoplasm of a previously engineered prokaryotic cell, SHuffle. Accumulated $\mathrm{H}_{2} \mathrm{O}_{2}$ pools were coupled to disulfide bond formation by the co-expression of PDI-GPx7 fusions. The feasibility of this redox-coupled system was demonstrated on the most profitable therapeutic protein, Humira IgG. Co-expression of human PDI-GPx7 fusion improved the correct assembly and yield of Humira IgG in highdensity fermentations by several folds.

\section{Materials and methods}

\section{E. coli strains and plasmids}

Bacterial strains and plasmids used in this work are described in Table 1 and were constructed using a standard molecular and genetic technique (Sambrook et al. 1989). NEB 10-beta competent E. coli (New England Biolabs, cat. No. C3019) was used for plasmid cloning procedures and transformed by heat shock transformation, following the manufacturer's instructions. Transformed cells were then selected on LB agar plates containing $30 \mu \mathrm{g} / \mathrm{mL}$ chloramphenicol or $200 \mu \mathrm{g} / \mathrm{mL}$ ampicillin where appropriate. SHuffle B T7 express E. coli cells (New England Biolabs, cat. No. C3029) were used as hosts for protein expression and purification studies. 
Table 1 Bacterial strains and plasmids utilized in this study

\begin{tabular}{|c|c|c|}
\hline Strains & \multicolumn{2}{|l|}{ Relevant genotype } \\
\hline $\begin{array}{l}\text { SHuffle express T7 } \\
\text { (C3029) }\end{array}$ & \multicolumn{2}{|c|}{ 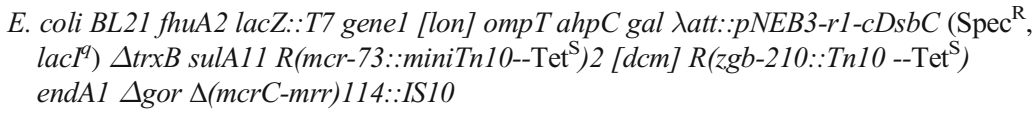 } \\
\hline MB2797 & \multicolumn{2}{|l|}{ C3029 + pBAD34 - KatG-FLAG } \\
\hline MB4638 & \multicolumn{2}{|l|}{ C3029 + pACYC Duet } \\
\hline MB6226 & \multicolumn{2}{|c|}{ C3029 + pACYC Duet - PDI-hsa Gpx7-Flag (SHuffle2) } \\
\hline MB6227 & \multicolumn{2}{|c|}{ C3029 + pACYC Duet - PDI-mmu Gpx7-Flag } \\
\hline MB6228 & \multicolumn{2}{|l|}{ C3029 + pACYC Duet - PDI-dre Gpx7-Flag } \\
\hline MB6229 & \multicolumn{2}{|l|}{ C3029 + pACYC Duet - PDI-lak Gpx7-Flag } \\
\hline MB6230 & \multicolumn{2}{|l|}{ C3029 + pACYC Duet - PDI-aqu Gpx7-Flag } \\
\hline MB6231 & \multicolumn{2}{|l|}{ C3029 + pACYC Duet - PDI-gga Gpx7-Flag } \\
\hline MB6232 & \multicolumn{2}{|l|}{ C3029 + pACYC Duet - PDI-pxb Gpx7-Flag } \\
\hline MB6233 & \multicolumn{2}{|l|}{ C3029 + pACYC Duet - cPDI-Gpx7-Flag } \\
\hline MB6165 & C3029 + pACYC Duet & $+\mathrm{pET} 23 \mathrm{~b}$ \\
\hline MB4135 & C3029 & + pHumira \\
\hline MB6209 & C3029 + pACYC Duet & + pHumira \\
\hline MB6201 & C3029 + pACYC Duet - PDI-hsa Gpx7 & + pHumira (SHuffle2) \\
\hline MB6202 & C3029 + pACYC Duet - PDI-mmu Gpx7 & + pHumira \\
\hline MB6203 & C3029 + pACYC Duet - PDI-dre Gpx7 & + pHumira \\
\hline MB6204 & C3029 + pACYC Duet - PDI-lak Gpx7 & + pHumira \\
\hline MB6205 & C3029 + pACYC Duet - PDI-aqu Gpx7 & + pHumira \\
\hline MB6206 & C3029 + pACYC Duet - PDI-gga Gpx7 & + pHumira \\
\hline MB6207 & C3029 + pACYC Duet - PDI-pxb Gpx7 & + pHumira \\
\hline MB6208 & C3029 + pACYC Duet - cPDI-Gpx7 & + pHumira \\
\hline MB6210 & C3029 + pACYC Duet - Gpx7-hsa-Flag & + pHumira \\
\hline Plasmids & Features & \\
\hline
\end{tabular}

pHumira

pACYC Duet

pACYC Duet-PDI-lak GPx7-FLAG

Humira antibody cloned into pETDuet NdeI/XhoI site by Gibson Assembly of PCR product of LC and HC, under the regulation of T7 promoter, pBR322 origin, AmpR.

Vector encodes two multiple cloning sites (MCS) under the control of T7 promoter, lac operator and ribosome binding site. pACYC origin, CamR.

Source

NEB cat\# C3029

This study

This study

This study

This study

This study

This study

This study

This study

This study

This study

This study

This study

This study

This study

This study

This study

This study

This study

This study

This study

This study

This study

Source

(Leith et al. 2019)

Novagen cat\# 71146-3

E. coli codon optimized PDI-GPx7 fusion from Lingula anatina (PDI Accession Number This study XP_013416130.1 and GPx7 Accession Number XP_013409653.1) was synthesized and cloned into pACYC Duet (NcoI/SalI). 3' Flag tag was inserted using the primers NK1012-FLAG-r and NK1016-lak-f. pACYC origin, CamR.

pACYC Duet-PDI-pxb GPx7-FLAG

E. coli codon optimized PDI-GPx7 fusion from Pyrus $x$ bretschneideri (Chinese white pear, PDI Accession Number XP_009335086.1 and GPx7 Accession Number XP 009359105.1) was synthesized and cloned into pACYC Duet (NcoI/SalI). 3' Flag tag was inserted using the primers NK1012-FLAG-r and NK1014-pxb-f. pACYC origin, CamR.

pACYC Duet-PDI-aqu GPx7-FLAG

E. coli codon optimized PDI-GPx7 fusion from Amphimedon queenslandica (Sponge PDI This study Accession Number XP_003382810.1 and GPx7 Accession Number XP_003388439.1) was synthesized and cloned into pACYC Duet (NcoI/SalI). 3' Flag tag was inserted using the primers NK1012-FLAG-r and NK1015-aqu-f. pACYC origin, CamR.

pACYC Duet-PDI-dre GPx7-FLAG

E. coli codon optimized PDI-GPx7 fusion from Danio rerio (Zebrafish PDI Accession Number NP_998529.3 and GPx7 Accession Number NP_001018337.1) was synthesized and cloned into pACYC Duet (NcoI/SalI). 3' Flag tag was inserted using the primers NK1012-FLAG-r and NK1017-dre-f. pACYC origin, CamR.

pACYC Duet-PDI-gga GPx7-FLAG E. coli codon optimized PDI-GPx7 fusion from Gallus gallus (Chicken PDI Accession Number NP_001185639.2 and GPx7 Accession Number NP_001156717.1) was synthesized and cloned into pACYC Duet (NcoI/SalI). 3' Flag tag was inserted using the primers NK1012-FLAG-r and NK1018-gga-f. pACYC origin, CamR.

pACYC Duet-PDI-hsa GPx7-FLAG
This study

This study

This study

e

E. coli codon optimized PDI-GPx7 fusion from Homo sapiens (Human PDI Accession Number NP 000909.2 and GPx7 Accession Number NP 001139309.1) was synthesized and cloned into pACYC Duet (NcoI/SalI). 3' Flag tag was inserted using the primers NK1012-FLAG-r and NK1020-hsa-f. pACYC origin, CamR. 
Table 1 (continued)

pACYC Duet-PDI-mmu GPx7-FLAG E. coli codon optimized PDI-GPx7 fusion from Mus musculus (Mouse PDI Accession Number NP_035162.1 and GPx7 Accession Number NP 077160.1) was synthesized and cloned into pACYC Duet (NcoI/Sall). 3' Flag tag was inserted using the primers NK1012FLAG-r and NK1019-mmu-f. pACYC origin, CamR.

pACYC Duet-hsa-GPx7- FLAG primers 5'-nsGpx7 and 3'-nsGpx7. pACYC origin, CamR.

Low copy number pACYC Duet plasmids (Novagen cat. No. 71147) with a strong $\mathrm{T} 7$ promotor were used to express GPx7-PDI fusion genes (Table 1). The fusion constructs were designed in silico with a 17 amino acid linked in between PDI and GPx7 and synthesized by Genescript (www.genscript. com) with codons optimized for $E$. coli expression in pACYC Duet plasmid between NcoI and SalI restriction sites. A FLAGX3 tag was introduced in $3^{\prime}$ end by PCR using the primers listed in Supplementary Table S1 and the description of the use of primers in constructing plasmids is listed in Supplementary Table S2.

\section{Shake-flask culture growth conditions}

Overnight cultures of $5 \mathrm{~mL}$ Rich media $(10 \mathrm{~g} / \mathrm{L}$ soy peptone, $5 \mathrm{~g} / \mathrm{L}$ yeast extract, $5 \mathrm{~g} / \mathrm{L} \mathrm{NaCl}, \mathrm{NaOH}$ to $\mathrm{pH}$ 7.2) with the appropriate antibiotics were used to inoculate $1 / 100$ th $v / \mathrm{v}$ $25 \mathrm{~mL}$ shake-flask cultures and grown at $30{ }^{\circ} \mathrm{C}$ for $3 \mathrm{~h}$ until $\mathrm{OD}_{600}$ reached 0.8 . The cultures were then induced with $500 \mu \mathrm{M}$ isopropyl- $\beta$-D-thiogalactopyranoside (IPTG) and grown at $16^{\circ} \mathrm{C}$ overnight or for $5 \mathrm{~h}$ at $30^{\circ} \mathrm{C}$ with shaking at $220 \mathrm{rpm}$. Cells were harvested by centrifugation and frozen at $-20{ }^{\circ} \mathrm{C}$. Cells densities were then standardized to the same ratio $\mathrm{OD}_{600}$ value using lysis buffer $(1 \times \mathrm{PBS}, 5 \%$ glycerol, $1 \mathrm{mM}$ EDTA) and consequently lysed by sonication. The total fraction $(T)$ was then centrifuged for $15 \mathrm{~min}$ at $20,000 \times \mathrm{g} 4{ }^{\circ} \mathrm{C}$. Proteins in the soluble fraction $(S)$ were quantified with BCA reagent (BCA Protein Assay kit, Pierce, cat. No. 23225). The expression and activity of the oxidative substrate were then analyzed by western blot and/or ELISA assays, where appropriate.

\section{High-density fermentation growth conditions}

Seed cultures were inoculated by adding a single colony from the streaked plates into $250 \mathrm{~mL}$ Erlenmeyer flasks containing $125 \mathrm{~mL}$ of selective LB liquid medium. The seed cultures were grown at $30{ }^{\circ} \mathrm{C}$, shaking at $275 \mathrm{rpm}$ for $14 \mathrm{~h}$, and then immediately used to inoculate DASGIP ${ }^{\circledR}$ BioBlock fermenters containing $1 \mathrm{~L}$ complex medium $(1.2 \%$ soytone, $2.4 \%$ yeast extract, $4 \mathrm{mM}$ potassium hydroxide, $2 \%$ glycerol, $25 \mathrm{mM}$ dibasic potassium phosphate, $0.05 \%$ antifoam $204,1 \times$ DeLissa Trace metals, and selective antibiotics). The fermenters were controlled by a computer running DASware software (Eppendorf, Hauppauge, NY). The pH was maintained at 7.0 using $28 \%$ ammonium hydroxide and $10 \%$ phosphoric acid. The cultures were grown at $30{ }^{\circ} \mathrm{C}$ and agitated at an initial speed of $500 \mathrm{rpm}$. When the dissolved oxygen reached $30 \%$ air saturation, an agitation/gas flow/oxygen enrichment cascade was used to maintain this level of oxygenation. After 9 to $10 \mathrm{~h}$ of growth, IPTG was added to a final concentration of $0.4 \mathrm{mM}$ in the fermenter. One milliliter of culture was sampled throughout the experiments and used to monitor metabolite production/nutrient consumption and recombinant protein production. After recording the density of the culture, the samples were centrifuged at $13,000 \mathrm{rpm}$ for $75 \mathrm{~s}$, and the cell pellet was collected and stored at $-20{ }^{\circ} \mathrm{C}$. Cells were resuspended into lysis buffer at $\mathrm{OD}_{600}=50.1 \mathrm{~mL}$ of the resuspended cells was sonicated at $40 \%$ maximum amplitude for $2 \mathrm{~min}$ at $2 \mathrm{~s}$ on and $4 \mathrm{~s}$ off setting for three rounds. Insoluble matter was removed by $15 \mathrm{~min}$ and 13,000 rpm centrifugation and the soluble supernatant fractions were collected.

\section{PDI and GPx7 bioinformatic analysis}

Mouse GPx7 sequence (NP_077160.1) without the ERretention signal was used as bait to search NCBI nr database restricted to eukaryotes via DELTA-BLAST (Boratyn et al. 2013). Retrieved sequences were manually curated for domain topology, ER-retention signal, and length using SMART (http://smart.embl-heidelberg.de, (Letunic and Bork 2011) and Signal P (http://www.cbs.dtu.dk/services/SignalP, (Petersen et al. 2011). Sequences were aligned with Clustal Omega (http://www.ebi.ac.uk/Tools/msa/clustalo, (Sievers et al. 2011) and trees made with same program, using default parameter (Blackshields et al. 2010). Dendrograms were plotted with iToL (http://itol.embl.de, (Letunic and Bork 2011)) and manually edited for presentation. To clone the respective PDI homologs from each selected organism, the closest homolog to human protein disulfide isomerase precursor (PDI, NP_000909) were chosen and cloned $5^{\prime}$ to its respective GPX7. A synthetic consensus sequence of GPx7 and PDI was designed by retaining the conserved residues of the aligned homologs based on previously described methods (Sternke et al. 2019). 


\section{Redox state analysis}

The in vivo redox state of the fusion proteins was determined by trapping free thiol groups with 4-acetamido-4'maleimidylstilbene-2,2'-disulfonic acid (AMS, Life Technologies, cat. No. A-485) following published protocols (Ke and Berkmen 2014). Briefly, $1 \mathrm{~mL}$ of induced culture at $\mathrm{OD}_{600} 0.5$ was transferred to $1.5 \mathrm{~mL}$ tubes containing $0.2 \mathrm{~mL}$ of $100 \%$ Trichloroacetic Acid (TCA, Fisher Scientific, cat. No. A322). Samples were mixed thoroughly by vortexing and incubated on ice for at least $20 \mathrm{~min}$. Precipitated proteins were centrifuged $15 \mathrm{~min}$ at $16,000 \times \mathrm{g}$ at $4{ }^{\circ} \mathrm{C}$ and $0.6 \mathrm{~mL}$ cold acetone was added to the pellet. Samples were vortexed briefly and incubated for $20 \mathrm{~min}$ on ice. After the wash step, proteins were centrifuged $15 \mathrm{~min}$ at $16,000 \times \mathrm{g}$ at room temperature and the pellet was air dried for $15 \mathrm{~min}$. Three experiments were prepared for each sample. As a positive control for AMS alkylation, precipitated samples were dissolved in $0.2 \mathrm{~mL}$ of $100 \mathrm{mM}$ Tris-Cl pH 6.8 with $0.1 \mathrm{mM}$ DTT and $1 \%$ SDS. After complete resuspension of the protein precipitate in $0.9 \mathrm{~mL}$ of $100 \mathrm{mM}$ Tris-Cl, $\mathrm{pH} 8.0$, samples were added to $0.2 \mathrm{~mL} 100 \%$ TCA to repeat the protein precipitation step. DTT was omitted in the test sample. Precipitated proteins from the positive control and test sample were resuspended in $80 \mu \mathrm{L}$ of $100 \mathrm{mM}$ Tris-Cl, pH 6.8 containing $10 \mathrm{mM}$ AMS and 1\% SDS. A negative control was included omitting AMS in the resuspension buffer. Proteins were completely dissolved by mixing tubes for $20 \mathrm{~min}$ at room temperature. The AMS alkylation reaction was then performed at $37^{\circ} \mathrm{C}$ for $40 \mathrm{~min}$. The oxidative state of the proteins was analyzed by immunoblotting using the primary anti-FLAG Tag (9A3) mouse mAb (Cell Signaling Technology, cat. No. 8146) and the secondary DyLight $^{\mathrm{TM}}$ IgG (Cell Signaling Technology, anti-mouse 800 conjugate cat. No. 5257).

\section{Western blot}

Protein samples were diluted in 1X Loading Buffer (New England Biolabs, cat. No. B7709) with or without DTT and loaded on Novex ${ }^{\mathrm{TM}} 4-20 \%$ Tris-Glycine pre-cast gel (ThermoFisher Scientific, WedgeWell ${ }^{\mathrm{TM}}$ format). SDS-PAGE was performed for $1 \mathrm{~h}$ at $45 \mathrm{~mA}$ per gel and proteins were transferred on PVDF membrane (BioRad, cat. No. 170-4157) using semi-dry blotting bio-rad protocol (BioRad, Trans-Blot ${ }^{\circledR}$ Turbo $^{\text {TM }}$ Blotting System, cat. No. 170-4155) for $7 \mathrm{~min}$ at 2.5 A. Membranes were blocked with Odyssey Blocking Buffer (LI-COR Biosciences, cat. No. 927-40,000) for $1 \mathrm{~h}$ at room temperature with gentle shaking and washed 3 times with PBS, $0.05 \%$ Tween for $5 \mathrm{~min}$, with shaking. The primary antibody (anti-Flag-Tag (9A3) mouse mAb (Cell Signaling Technology, cat. No. 8146) was diluted in Odyssey Blocking Buffer with $0.2 \%$ Tween and incubated with the membrane overnight at $4{ }^{\circ} \mathrm{C}$. The next day, membranes were washed as before and incubated with corresponding secondary DyLight ${ }^{\mathrm{TM}}$ IgG (Cell Signaling Technology, anti-mouse 800 conjugate cat. No. 5257) diluted in Odyssey Blocking Buffer, $0.2 \%$ Tween, $0.02 \%$ SDS for $1 \mathrm{~h}$ with gentle shaking, protected from light. After a last wash step, membranes were scanned on an Odyssey Imaging System.

\section{IgG purification}

IgG was induced in SHuffle2, cells were harvested and the cell pellet was resuspended into $1 \mathrm{~mL}$ lysis buffer (1XPBS with 5\% glycerol and $1 \mathrm{mM}$ EDTA) to OD 50. The $1 \mathrm{~mL}$ cell suspension was sonicated with mini tipped sonicator for $1 \mathrm{~min}(4 \mathrm{~s}$ on and $2 \mathrm{~s}$ off) and repeated three times. The sonicated cell suspension was spun at 13,000 rpm for $15 \mathrm{~min}$. The supernatant containing the soluble fractionation was separated from the insoluble pellet and subjected to purification. IgG was purified from the soluble fraction by affinity using protein A magnetic beads (New England Biolabs, cat. No. S1425) following the "Antibody Purification" protocol as recommended in the Pierce ${ }^{\mathrm{TM}}$ Protein A Magnetic Beads manual (ThermoFisher, MAN0011856), using Thermo Scientific KingFisher Flex instrument (ThermoFisher, 5,400,640). The low $\mathrm{pH}$ of the eluate was neutralized by adding $5 \mu \mathrm{L}$ of Neutralization Buffer (20\% Tris base $\mathrm{pH}$ 9.5) and purified fraction was resolved by SDSPAGE under non-reducing and reducing conditions. Proteins bands were visualized by staining with SimplyBlue ${ }^{\mathrm{TM}}$ SafeStain (ThermoFisher Scientific, Invitrogen ${ }^{\mathrm{TM}}$, cat. No. LC6065). And yields of purified IgG was obtained by BCA assay (ThermoFisher, cat 23,225).

\section{ELISA}

The total amount of purified $\operatorname{IgG}$ was analyzed by sandwich ELISA by using the Adalimumab ELISA kit for the lowdensity expression (Eagle Biosciences, cat. No. IG-AA103) and the BioSim ${ }^{\mathrm{TM}}$ anti-Adalimumab ELISA kit for the highdensity expression (BioVision, cat. No. E4388). IgGcontaining samples were quantified with BCA reagent and an equivalent amount of total protein (typically 0.23 $0.06 \mu \mathrm{g}$ ) was applied to the plate. The procedure was followed as noticed in the manual of the ELISA assay kit and the optical density was measured at $450 \mathrm{~nm}$ within 15 after pipetting the stop solution.

\section{Nucleotide sequences}

Nucleotide sequences of the E. coli codon optimized PDIGPx7 fusions can be accessed via GenBank using the accession codes: For human (MT764745), mouse (MT764747), chicken (MT764744), zebrafish (MT764750), sponge (MT764749), pear (MT764748) and mollusk (MT764746) PDI-GPx7 fusions. 


\section{Results}

\section{Engineered redox pathway of SHuffle}

SHuffle cells have undergone genetic manipulations in order to optimize the formation of disulfide bonds in proteins expressed in the cytoplasm. The genetic manipulations can be summarized as disruption of the disulfide bond reductive pathways and selection for suppressors which permit the formation of disulfide bonds. Genes coding for thioredoxin reductase $(\operatorname{tr} x B)$ and glutathione reductase $(g o r)$ were deleted. This double $\Delta \operatorname{tr} x B, \Delta$ gor deletion is lethal as it abolishes the main reducing pathways responsible for maintaining the redox cycle of the cells. A suppressor of $\Delta \operatorname{trx} B, \Delta$ gor was selected to map to cytoplasmic alkyl hydroperoxide reductase $\mathrm{C}$ $(\mathrm{AhpC})$ which has lost the function as a peroxidase and gained the ability to reduced glutathionylated glutaredoxin-1 (Yamamoto et al. 2008). To further enhance the fidelity of disulfide bond formation, a chromosomal copy of cytoplasmic DsbC (cDsbC) was inserted, resulting in the final $\triangle \operatorname{tr} x B$, $\Delta$ gor, $\Delta a h p C^{*}+\mathrm{cDsbC}$ strain, named SHuffle (Lobstein et al. 2012). The lack of peroxidase activity of AhpC* induces oxidative stress (Reuter et al. 2019), presumably due to the increased amounts of $\mathrm{H}_{2} \mathrm{O}_{2}$ (Fig. 1).

To engineer a redox pathway, originally localized in the ER of a eukaryote, we produced various PDI-GPx7 fusion proteins in the cytoplasm of a prokaryote. Fusion of PDI to GPx 7 is assumed to increase the probability of a $\mathrm{H}_{2} \mathrm{O}_{2} \rightarrow \mathrm{GPx} 7 \rightarrow$ PDI $\rightarrow$ Humira redox relay pathway. This is mainly due to the transient and rapid cascades of oxidation by $\mathrm{H}_{2} \mathrm{O}_{2}$ (Wang et al.
2014). Consequently, by decreasing the proximity between GPx7 and PDI, $\mathrm{H}_{2} \mathrm{O}_{2}$ oxidized GPx7 would in turn oxidize PDI, recapitulating the PDI-GPx 7 redox cycle in its native ER compartment (Roberto Sitia and Tobias Dick, personal communications) (Fig. 1).

\section{Bioinformatic selection of PDI-GPX7 fusion pairs}

The ability of GPx 7 class of peroxidases to oxidize PDI has only been studied in the context of eukaryotic cells (BoselloTravain et al. 2013; Laurindo et al. 2012; Maiorino et al. 2015). Due to minimal pre-existing data on E. coli expressed GPx7, little is known regarding which PDI-GPx7 fusion couple would express, fold, and be active when expressed in the cytoplasm of SHuffle. In order to maximize the chances of expressing the correct couple, a simple bioinformatic approach was used. Starting with mouse GPx7 (NP_077160.1), a BLAST search for homologs was performed. To construct a simple phylogenetic tree, ClustalW was used to construct a sequence alignment and the final tree was visualized using iTol (Fig. 2a). From this tree, seven homologs of GPx 7 were chosen from separate phylogenetic nodes, spanning over the entire phylogenetic tree; Human (Homo sapiens), Mouse (Mus musculus), Chicken (Gallus gallus), Zebrafish (Danio rerio), Sponge (Amphimedon queenslandica), Pear (Pyrus x bretschneideri) and Mollusk (Lingula anatina) (Fig. 2b). A consensus sequence of GPx7 and PDI was also synthesized as described in materials and methods. Selected homologs all share (1) conserved active site cysteines, (2) N-terminal signal peptide, (3) C-terminal ER

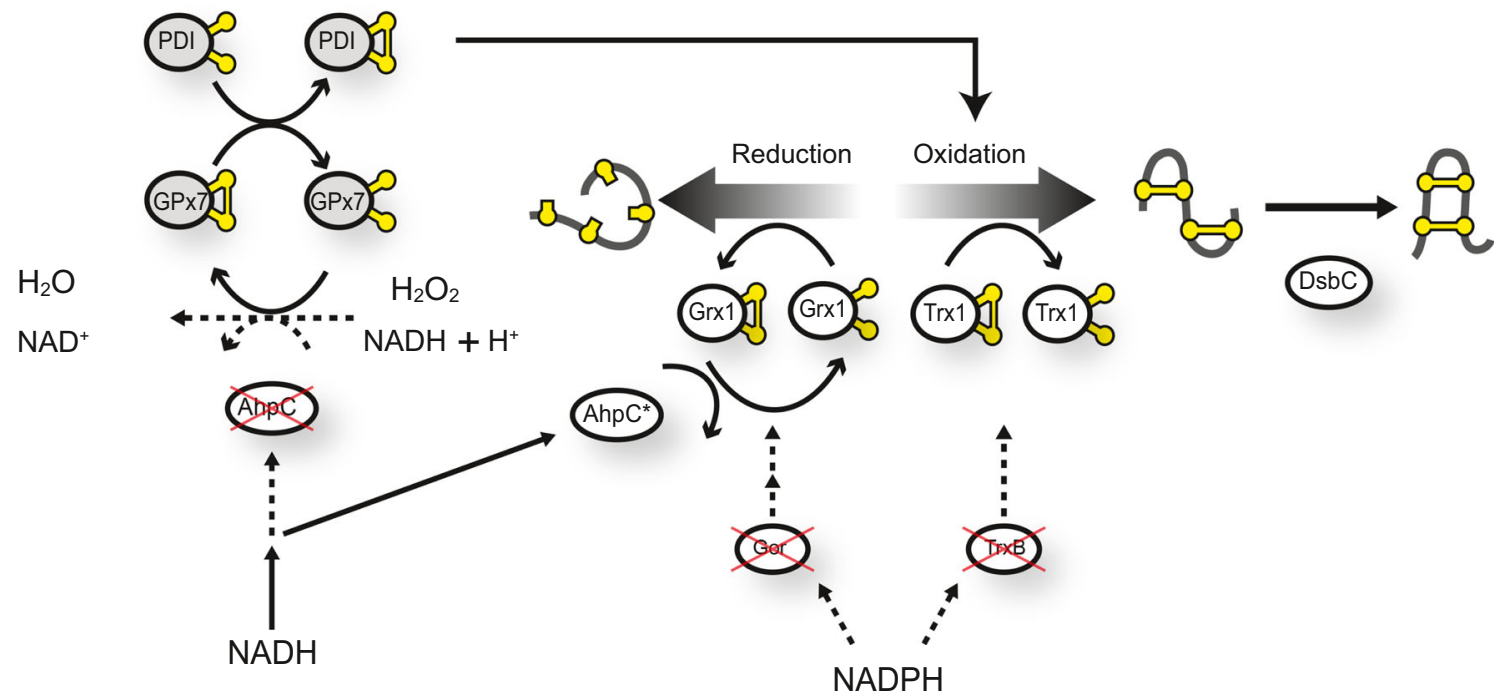

Fig. 1 Schematic representation of the redox pathway in SHuffle2. Genetic deletions of gor and $\operatorname{tr} x B$ genes disrupt the electron flow (dotted lines) to the glutathione (Grx) and thioredoxin (Trx) reductases, resulting in lethality. Suppressors are mapped to the mutant peroxidase $\mathrm{AhpC}^{*}$, which has lost its peroxidase activity and instead has gained the ability to reduce Grx1. Oxidized thioredoxin ( $\operatorname{Tr} 1)$ facilitates the oxidation of proteins, which are further isomerized by the cytoplasmic expression of disulfide bond isomerase, DsbC. The lack of peroxidase activity of AhpC* results in accumulation of $\mathrm{H}_{2} \mathrm{O}_{2}$. Expression of PDIGPx7 fusions (here shown as separate proteins for clarity) results in the oxidation of $\mathrm{GPx} 7$ by $\mathrm{H}_{2} \mathrm{O}_{2}$, which in turn oxidizes PDI who can then participate oxidation 
Fig. 2 Selection of GPx7 homologs. a Phylogenetic distribution of GPx7 homologs and selected candidates are indicated. The percentage amino acid sequence identity to human GPx7 is shown in brackets. b Representative view of the phylogeny from the selected GPx7 homologs. The FastTree was made without branch length from the eight Gpx7 homolog sequences. c Schematic representation of the $\mathrm{pACYC}$ Duet vector expressing the PDIGPx7 fusions. PDI and GPx7 peroxidases were fused by a polylinker of 17 amino acids and cloned under the regulation of a $\mathrm{T} 7$ promoter with a $\mathrm{C}$-terminal $3 \mathrm{X}$ Flag tag

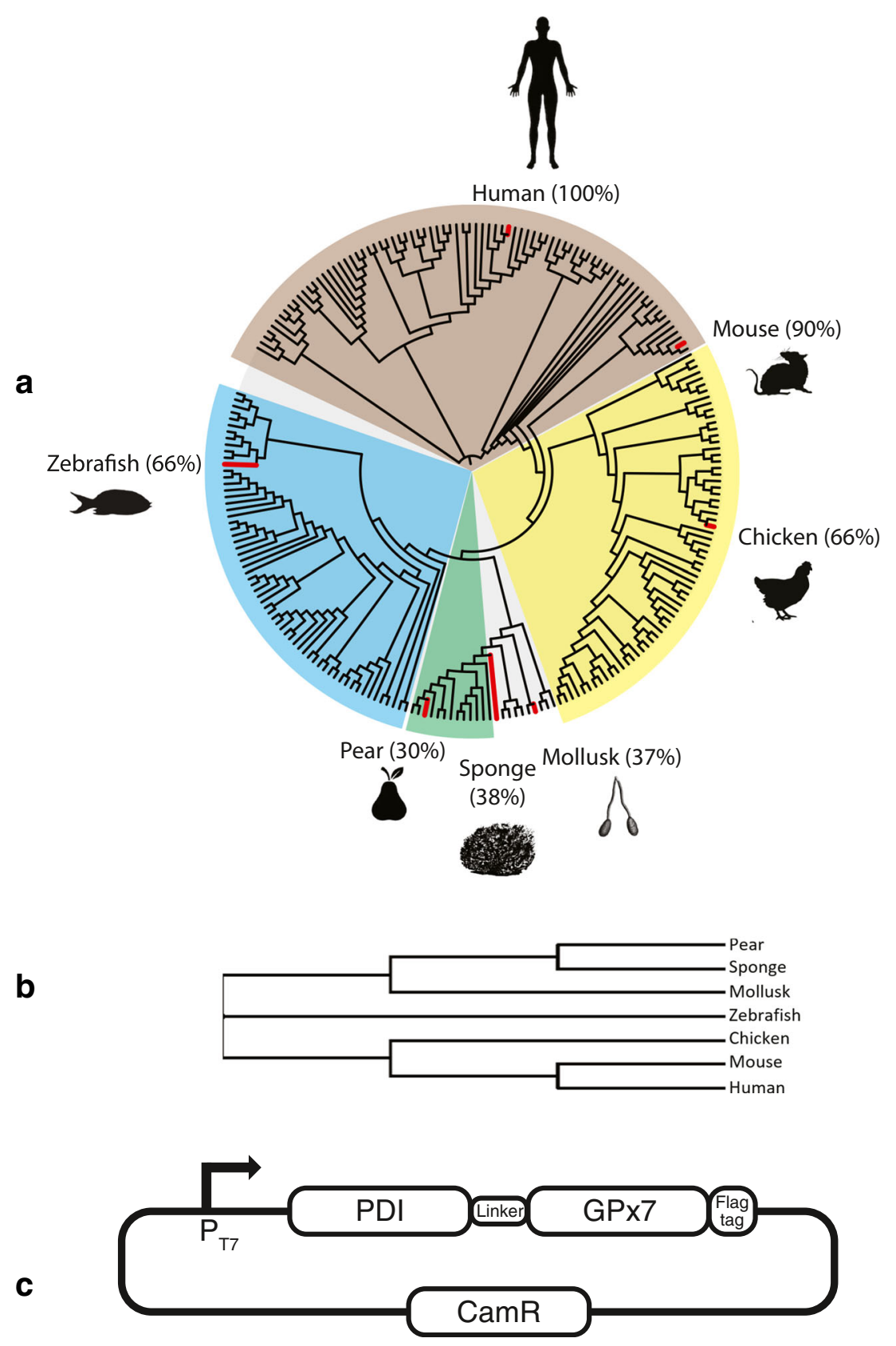

KDEL retention signal peptide, and (4) have conserved dimer interface sequence (Supplementary Fig. S1).

To construct the selected GPx7's fused to their cognate PDI partner, human PDI (PDI, NP 000909) was used to BLAST within the genomes of the selected organisms and those with highest homology were chosen. PDI was chosen as the Nterminal fusion as simple structural analysis indicated that PDI-linker-GPx 7 fusion is more favorable to allow the active sites of both PDI and GPx7 to potentially face each other. The final PDI-GPx7 couple was cloned as a fusion protein, using the 17 amino acid linker GSGSGSGSGSGSSGSGS (Foit et al. 2009), along with a C-terminal Flag tag and cloned into
pACYC-Duet plasmid under the regulation of the strong T7 promoter (Fig. 2c).

\section{Expression of PDI-GPx7 fusion pairs}

To evaluate whether SHuffle expressed PDI-GPx7 fusions with a C-terminal Flag tag were soluble and presumably correctly folded, a western blot analysis using anti-Flag tag antibodies was conducted on SHuffle cell lysates expressing various PDI-GPx7 fusions as described in materials and methods. In summary, cells were grown at $30{ }^{\circ} \mathrm{C}$ to mid-log, induced with $500 \mu \mathrm{M}$ IPTG and grown for an additional $5 \mathrm{~h}$. Cells 
were collected, subjected to lysis by sonication and an aliquot was removed to represent the total lysate (T). The insoluble fraction was pelleted by centrifugation and the supernatant fraction was collected to represent the soluble fraction (S). Samples were boiled in loading buffer, separated by SDSPAGE and subjected to western blot analysis using anti-Flag tag antibodies (Fig. 3).

As a negative control for cross reactivity of the Flag-tag antibody to proteins within the SHuffle lysate, cells harboring an empty pACYC-Duet vector were used (MB4638). Little to no background of the anti-Flag antibody was observed, indicating that the bands observed in flag-tagged samples are specific to the Flag epitope (Fig. 3, lane 1). SHuffle cells expressing pBAD34-KatG-flag (MB2797) were used as a positive control for the western blot and the major band at the expected size of $83 \mathrm{kDa}$ was observed, indicating that the western blot analysis functioned as expected with little to no cross reactivity (Fig. 3, lane 2). SHuffle cells expressing the various PDIGPx7 fusion proteins were similarly treated and the resulting blot analysis detected equal amounts of protein in the total and soluble fractions, suggesting PDI-GPx7 fusion proteins are mostly soluble (Fig. 3, lanes 3 to 18 , red boxes). Only the PDI-GPx7 fusion cloned from the pear plant resulted in comparatively weak expression, albeit was also soluble (Fig. 3, lanes 15,16$)$.

Even though the fusions were soluble, significant levels of other species were also observed. The smaller weight products may represent degradation products while the larger species may be mis-oxidized species. This is mostly likely due to the artificial fusions and incorrect folding of eukaryotic proteins in E. coli. Yet the majority of the species detected was in the expected size.

Digital analysis of the intensity of the Flag-tag detected protein bands using ImageJ, indicated that the PDI-GPx7 fusions at their expected sizes were on average $\sim 50 \%$ of the total protein bands in the soluble lysate. Expression of Mollusk and Sponge PDI-GPx7 fusions resulted in predominant protein bands below $30 \mathrm{kDa}$ (Fig. 3, lanes 9-12). These could correspond to cleaved fusion products, resulting in GPx7 $(\sim 20 \mathrm{kDa})$ and PDI ( 55 to $61 \mathrm{kDa})$.

\section{Redox state analysis of PDI-GPx7 fusion pairs}

Both PDI and GPx7 are redox-active enzymes involved in the formation of disulfide bonds. In their native ER compartment, the active site cysteines of mammalian (Appenzeller-Herzog and Ellgaard 2008) or yeast (Vitu et al. 2010) PDI within the CXXC motif are maintained mostly in their oxidized, disulfide-bonded state. PDI is maintained in its oxidized state by Ero1 (Ramming et al. 2015), while GPx7 is oxidized by $\mathrm{H}_{2} \mathrm{O}_{2}$, which in turn oxidizes PDI (Wang et al. 2014). In this study, an artificial redox pathway was engineered within SHuffle cells to promote disulfide bond formation relay via $\mathrm{H}_{2} \mathrm{O}_{2} \rightarrow$ GPx $7 \rightarrow$ PDI $\rightarrow$ Humira. In order to couple the oxidation of GPx 7 to the oxidation of PDI, the protein pair was expressed as a fusion.

PDI-GPx7 fusions contain two CXXC active sites in PDI and one in GPx7, totaling six cysteines involved in redox

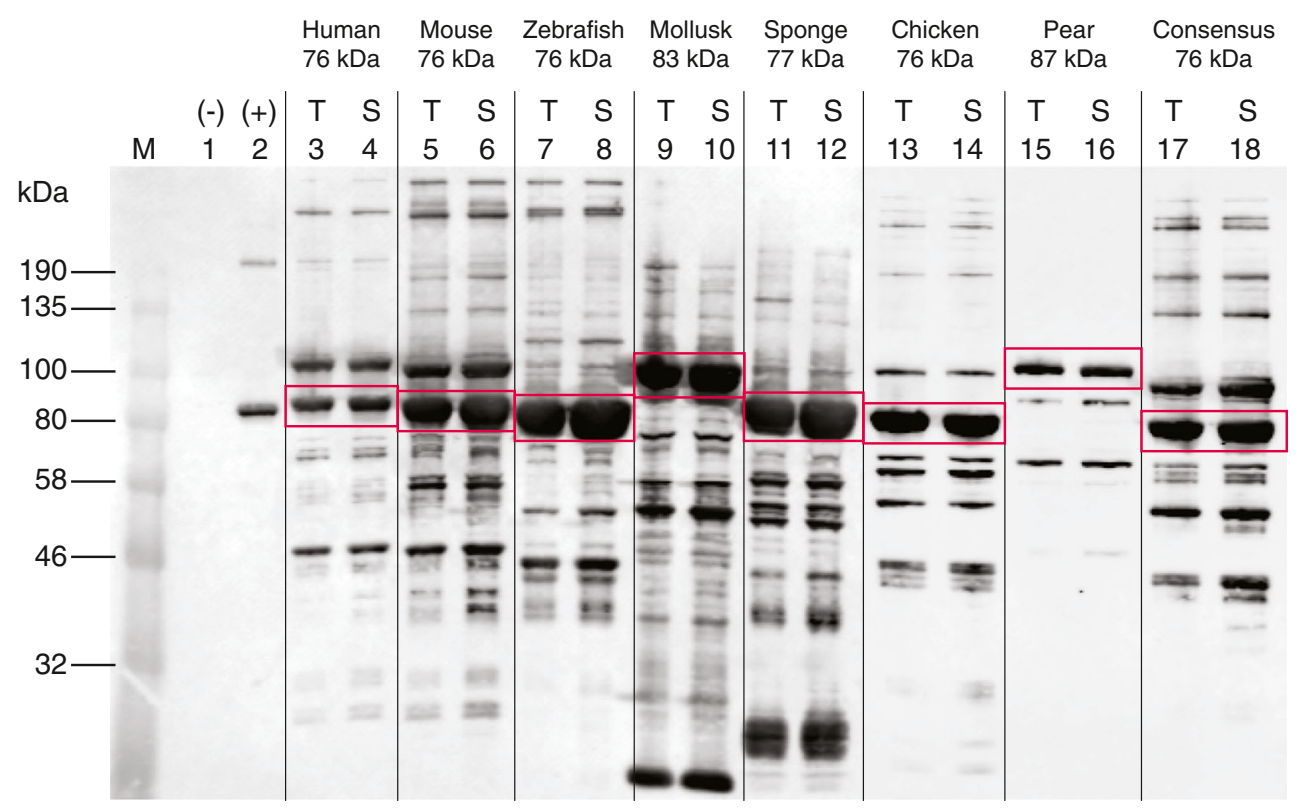

Fig. 3 SHuffle expressed Gpx7-PDI fusions are soluble. SHuffle cells expressing various PDI-GPx7 fusions were lysed by sonication (total fraction, $T$ ) and the insoluble fraction was removed by centrifugation, separating the soluble supernatant fraction $(S)$. Cells expressing empty vector was used as negative control (lane 1) and cells expressing flag- tagged KatG ( $83 \mathrm{kDa}$ ) was used as a positive control for the western blot (lane 2). Samples were separated by SDS-PAGE blotted on nitrocellulose paper and probed with anti-Flag antibodies. The molecular weight of the protein ladder is shown in the left. Protein bands at the expected size of the fusions are shown in red boxes (lanes 3 to 18 ) 
reactions. Only the fusion from sponge (Amphimedon queenslandica) has only redox-active cysteines, while all other fusions have 2-4 other presumably structural cysteines. In their native ER compartments, the active site cysteines are mostly in their oxidized, disulfide-bonded state. To investigate the redox states of the cysteines of the PDI-GPx7 fusion, AMS alkylation on soluble cell extracts was performed. AMS alkylates free thiol groups, covalently adding 500 Da per cysteine, resulting in a mobility shift in SDS-PAGE analysis (Berkmen 2012). Western blot analysis of the fusions using anti-Flag tag antibodies revealed that the fusions are mostly in their oxidized state (Fig. 4, lanes 3, 6, 9, 12, 15, 18, 25). Only the poorly expressing PDI-GPx7 fusion from pear (Pyrus $x$ bretschneideri) was detected to be mostly in its reduced state (Fig. 4, lane 22). A small shift in mobility is observed with the fusions when cell extracts were treated with AMS, indicating that the majority of the cysteines in the fusions are oxidized. When the mobility of AMS treated samples are compared to reduced samples treated with DTT (Fig. 4, lanes 1, 4, 7, 10, $13,16,23)$ a significant difference in mobility is observed. Supporting the conclusion that except for the fusion from pear, the rest of the PDI-GPx7 fusions are expressed mostly in their active, oxidized state in the cytoplasm of SHuffle cells.

\section{Selection of PDI-GPx7 fusion to fold Humira, in a shake-flask expression condition}

To select for the optimal PDI-GPx7 fusion which has the highest impact on the folding of Humira IgG, SHuffle strains expressing pHumira and $\mathrm{pET}$-Duet plasmids expressing the various PDI-GPx7 fusions were grown, induced and Humira IgG was purified from cell extracts as described in materials and methods. Protein A purified extracts normalized to cell density were separated by molecular weight in non-reducing SDS-PAGE (Fig. 5a). Compared to SHuffle cells expressing Humira with an empty vector (Fig. 5a, lane 9, MB6209), coexpression of PDI-GPx 7 fusions dramatically increased the protein band around the expected size of Humira IgG at
$150 \mathrm{kDa}$ (Fig. 5a, lanes 1-8). This process was repeated in three independent biological replicates. Intensity of the protein band representing the full-length IgG at $\sim 150 \mathrm{kDa}$ was standardized to a contaminating band found in all samples at $58 \mathrm{kDa}$ (Fig. 5a, protein band marked by a star $(*))$. The average intensity of Humira IgG from purified samples was calculated and presented in order of improvement (Fig. 5b). To address whether GPx7 is directly involved in the folding of Humira IgG independently of PDI, the MB6210 strain expressing GPx7 on its own was also evaluated for Humira $\mathrm{IgG}$ expression. Unlike the expression of the PDI-GPx7 fusion, the expression of Gpx 7 alone had marginal improvement on the folding of Humira IgG (Fig. 5b). To confirm the positive impact of the human PDI-GPx7 on the high level of Humira IgG production, ELISA assays were performed towards the antigen (TNF $\alpha$ ), from purified IgG extracts produced in SHuffle wt cells (MB6209) or in the SHuffle2 strain co-expressing human PDI-GPx7 fusion (MB6201). Protein concentration of the purified fraction was measured for each extract and the final yields of $\operatorname{IgG}$ obtained in the purified fraction were calculated as $427 \mathrm{mg} / \mathrm{L}$ Humira from SHuffle2 (MB6201) and $168 \mathrm{mg} / \mathrm{L}$ Humira for SHuffle (MB6209), an improvement of more than 2-fold in SHuffle2 grown in shake flask (Fig. 5c). Taken together, the human PDI-GPx7 fusion demonstrated the highest potential to improve the folding of Humira IgG and was selected for further characterization.

\section{Evaluation of SHuffle2 in high-density expression of Humira}

Production of proteins at large scales is usually conducted in high-density fermenters. It is therefore important to validate the positive impact of human PDI-GPx7 on the folding of Humira IgG, in conditions similar to industrial processes.

Cells were grown to high density in a Dasgip BioBlock fermenters containing $1 \mathrm{~L}$ of complex medium. Three different $E$. coli cells were used to evaluate Humira IgG expression, SHuffle cells with their oxidizing cytoplasm harboring empty

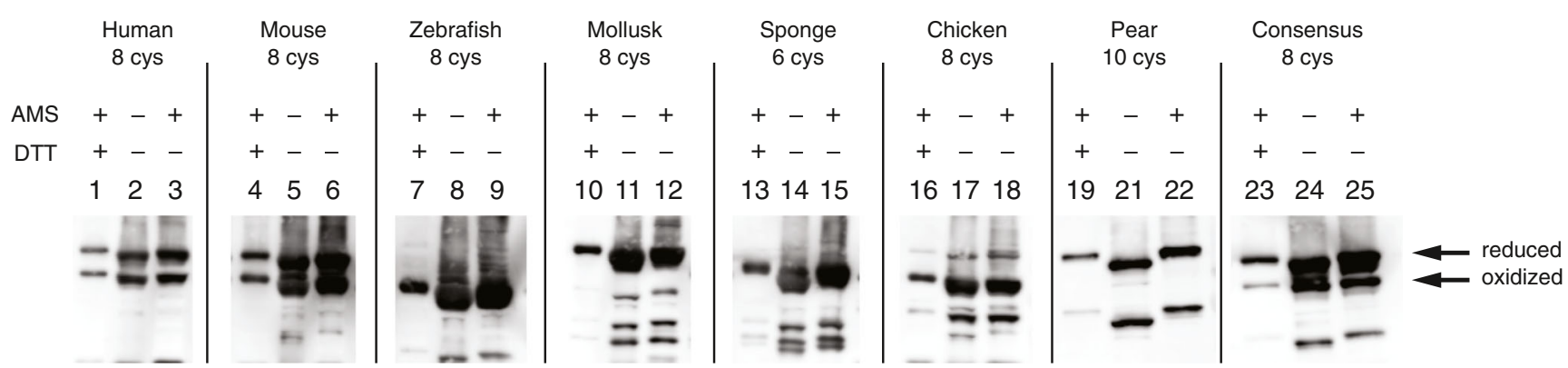

Fig. 4 Redox states of SHuffle expressed Gpx7-PDI fusions. SHuffle cells expressing various PDI-GPx7 fusions were precipitated with TCA and pellets were either resuspended in loading buffer representing the fully oxidized species (lanes $2,5,8,11,14,17,21,24)$ or samples were first reduced with DTT followed by AMS alkylation representing the fully reduced species (lanes 1, 4, 7, 10, 13, 16, 19, 23). Redox state of the fusions was evaluated by resuspending the samples in loading buffer with AMS (lanes 3, 6, 9, 12, 15, 18, 22, 25). The number of cysteines in the fusions is shown 
Fig. 5 SHuffle expression of Humira IgG is improved by Gpx7-PDI fusions. a Effects of PDI-GPx 7 fusions on the folding of Humira $\mathrm{IgG}$ is evaluated by protein A purification from soluble SHuffle lysates grown in shake-flask conditions. Samples were separated in non-reducing SDS-PAGE. The expected size of Humira $\operatorname{IgG}(150 \mathrm{kDa})$ is indicated with an arrow. Data are representative of three independent experiments. b Evaluation of PDI-GPx7 fusions on the Humira IgG folding conducted by quantifying the intensity of the band representing Humira to a contaminating band used to normalize loading amounts $(*),(n=3)$. One-way ANOVA with alpha $=0.05, * * * p$ value $\leq 0.001$, ** $p$ value $\leq 0.01$, $* p$ value $\leq 0.05$. c Yields of protein A purified Humira antibody, produced in SHuffle or SHuffle2 strains grown in shake flasks from three independent cultures $(n=3)$. Unpaired $t$ test with alpha $=0.05, * * p$ value $\leq$ 0.01
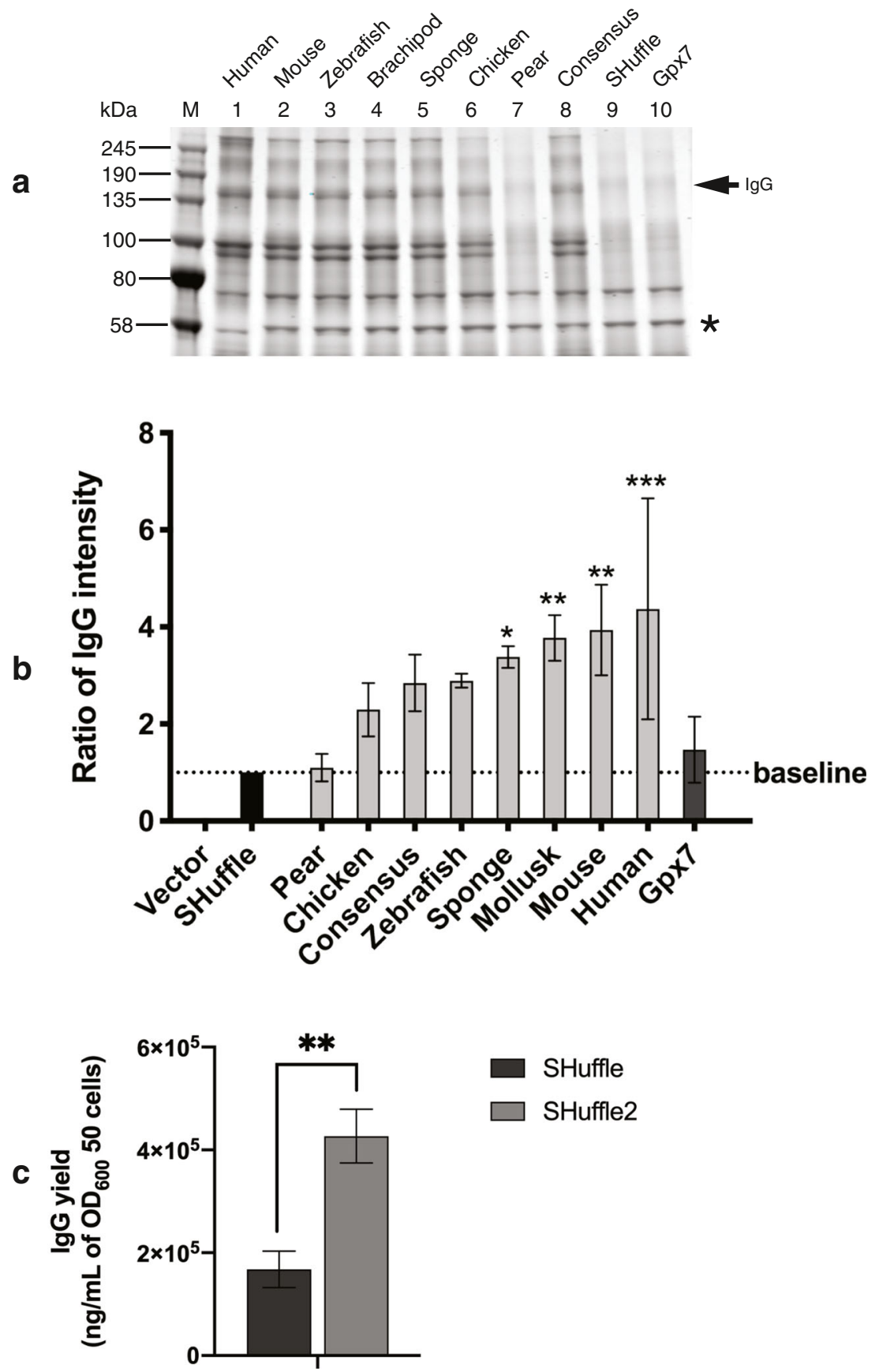

vectors as a control for background (MB6209), SHuffle cells expressing Humira IgG (MB4135), and SHuffle2 cells coexpressing human PDI-GPx7 (MB6201). Cells were collected and lysed and the Humira IgG was purified from the soluble lysate of cells, using protein A as described in "Materials and methods." Humira IgG produced in high density was first analyzed by running an aliquot of purified samples in SDSPAGE under non-reducing conditions. This process was repeated in triplicates for wild type (wt) and SHuffle2 (SH2) cells and in duplicates for SHuffle (SH) cells (Fig. 6a). The Humira full length correctly assembled IgG tetramer was observed at the expected size of $\sim 150 \mathrm{kDa}$, but as was not the major species. Unassembled light chain (LC, $25 \mathrm{kDa}$ ) and heavy chain $(\mathrm{HC}, 50 \mathrm{kDa}$ ) peptides were also observed, indicative that the expression levels are not limiting. Supporting the notion that the limiting factor is the correct assembly of LC and $\mathrm{HC}$, higher molecular weights protein bands above $200 \mathrm{kDa}$ were observed. Previous studies on expression and purification of IgG from SHuffle cells have observed similar mis-assembled IgG species that are mis-oxidized, as these high-molecular bands collapse into LC or HC, under reducing conditions (Leith et al. 2019; Lobstein et al. 2012; Reddy et al. 


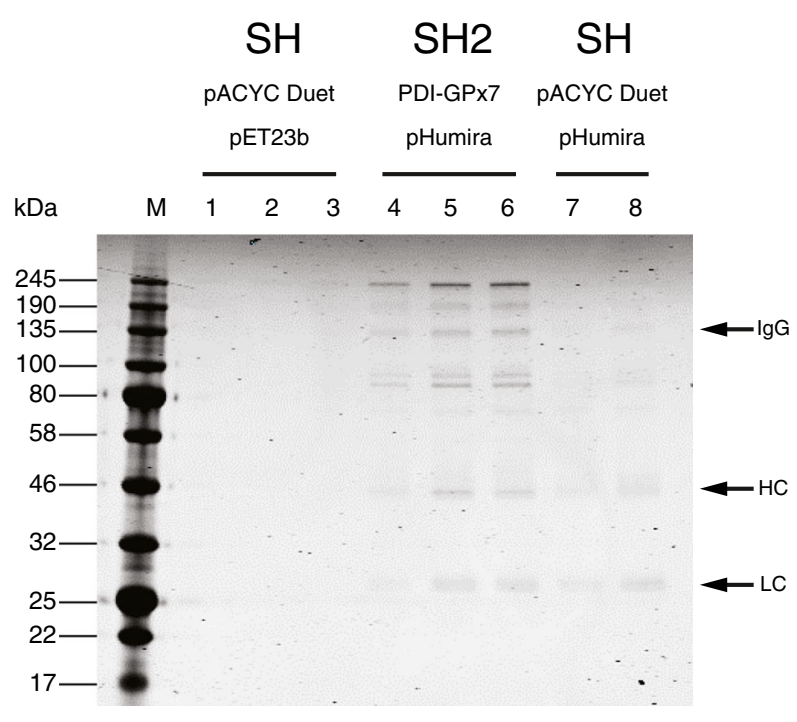

a

Fig. 6 High-density fermentation of Humira IgG expression is improved in SHuffle2. a Expression of Humira IgG was evaluated in SHuffle cells harboring empty vector (MB4135 lanes 1-3), in SHuffle cells expressing Humira IgG (MB6209, lanes 7-8), or in SHuffle2 cells expressing Humira IgG and co-expressing human PDI-Gpx7 fusion (MB6201, lanes 4-6). Purified Humira IgG was analyzed in SDS-PAGE under

2018). Binding capacity to Humira IgG's cognate antigen $\mathrm{TNF} \alpha$ was measured by ELISA and IgG concentration of the purified extracts were calculated (Fig. 6b). Results indicated that a 3-4-fold improvement in the final yields of IgG was observed when Humira IgG was expressed in SHuffle 2 compared to parental SHuffle strain. Taking the complete data set presented, the co-expression of the human PDI-GPx7 fusion in SHuffle cells, improve the expression and folding of Humira $\mathrm{IgG}$ in an industrially relevant manner.

\section{Discussion}

Expression of antibodies in E. coli merges the potentials of antibody-based technologies with $E$. coli genetics. A major limitation in expressing recombinant proteins in the cytoplasm of $E$. coli is the lack post-translational modification systems, such as disulfide bond formation. This study succeeded in coupling metabolic oxidant $\mathrm{H}_{2} \mathrm{O}_{2}$ to disulfide bond formation, via the expression of a synthetic eukaryotic pathway in a genetically engineering prokaryotic host. Success of this synthetic system was demonstrated by improving the yield of the most profitable protein, an IgG against rheumatoid arthritis, Humira.

This preliminary study indicates that the concept of utilizing the oxidation power of $\mathrm{H}_{2} \mathrm{O}_{2}$ to couple to disulfide bond formation, by redox engineering of a eukaryotic pathway into a prokaryotic system is feasible. In order to select the correct eukaryotic redox system, several attempts were made to

\section{IgG yield}

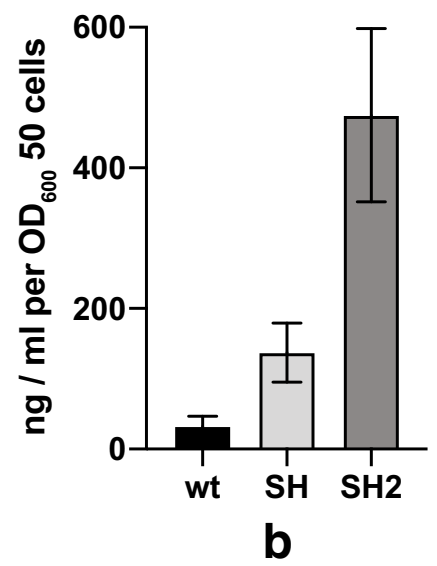

non-denaturing conditions. Full length correctly assembled IgG and unassembled Heavy Chain (HC) and Light Chain (LC) are indicated by arrows. b Humira IgG yields from wild type SHuffle cells (wt, MB4135), SHuffle control cells carrying the pACYC Duet plasmid (SH, MB6209), and SHuffle2 cells (SH2, MB6201) grown in high-density from two or three independent cultures

evaluate the functionality of various eukaryotic systems. A close homolog of GPx7 is GPx8, which shares the highest structural similarity and has similar capacity to oxidize PDI via $\mathrm{H}_{2} \mathrm{O}_{2}$ but has different biological roles in stress response. This study focused on GPx7 as it has one order of magnitude higher reactivity than GPx 8 towards $\mathrm{H}_{2} \mathrm{O}_{2}$ and is not anchored to the membrane as GPx 8 is predicted to have a type I transmembrane domain (Wang et al. 2014). Another class of peroxidase that can oxidize PDI is Prx4 (Tavender et al. 2010). Prx 4 can also catalyze de novo disulfide bond formation by reducing $\mathrm{H}_{2} \mathrm{O}_{2}$ but it expresses poorly in SHuffle cells (data not shown) and unlike GPx7, has a minor phenotype in knock-out mouse (Iuchi et al. 2009). Further, oxidation of a substrate protein by PDI was significantly slower in the presence of Prx4, compared to GPx7 (Nguyen et al. 2011). These preliminary attempts resulted in picking PDI-GPx 7 fusions as the candidates to engineer a new SHuffle system.

Even though elevated levels of $\mathrm{H}_{2} \mathrm{O}_{2}$ were confirmed in the cytoplasm of SHuffle (Reuter et al. 2019), the exact concentration of this transient and highly reactive oxidant is not known. It may therefore be possible that the levels of $\mathrm{H}_{2} \mathrm{O}_{2}$ are not sufficient and increasing the availability of $\mathrm{H}_{2} \mathrm{O}_{2}$ can improve GPx 7 driven disulfide bond formation. An enzymatic production of $\mathrm{H}_{2} \mathrm{O}_{2}$ was attempted by expressing ER resident Ero1 in pET-Duet to increase cytoplasmic concentration of $\mathrm{H}_{2} \mathrm{O}_{2}$. Erol can consume $\mathrm{O}_{2}$ to produce $\mathrm{H}_{2} \mathrm{O}_{2}$, but preliminary evidence using human Ero1 in SHuffle2 did not increase levels of Humira production (data not shown). Similarly, exogenous addition of $\mathrm{H}_{2} \mathrm{O}_{2}$ did not result in any observable 
improvement in Humira IgG folding (data not shown). This may be due to the highly reactive nature of $\mathrm{H}_{2} \mathrm{O}_{2}$ and thus perhaps a triple fusion of PDI-GPx7-Ero1 may supply $\mathrm{H}_{2} \mathrm{O}_{2}$ to GPx7 in close proximity. Further improvements in the production of Humira IgG could be also achieved by expressing a mutant version of Humira with a single silent mutation $\left(\mathrm{Val}_{216}\right.$ GTG mutated to synonymous GTT), as this version does not result in the re-initiation of the heavy chain (Leith et al. 2019).

Synthetic pathways often are trial and error attempts at engineering an artificial gene circuit and are not optimized by the selective processes of evolution. Although the designs of these systems can be guided by bioinformatic and system biology, functionality of these artificial systems often are specific for certain substrates under certain conditions. This was the case for the artificial PDI-GPx7 coupled redox pathway, engineered to improve IgG folding in SHuffle cells. Although great success was achieved in improving the folding of Humira IgG, little to no improvement was observed for two other IgG molecules tested, NIST mAb (Reddy et al. 2018) and anti-MBP (Lobstein et al. 2012) (data not shown). Many other IgG molecules and derivatives need to be evaluated under various expression conditions, to discern the specificity of the PDI-Gpx7 coupled disulfide bond formation in SHuffle cells.

Acknowledgements The authors would like to thank the creative, collaborative scientific environment that Don Comb has built and maintained by NEB management.

Authors' contributions G.R. proposed the hypothesis; M.L., N.K., C.Z. conducted majority of the experiments; H.S. supervised C.Z.; B.M. conducted the bioinformatic analysis; and M.B. supervised and wrote the manuscript. All authors edited.

\section{Compliance with ethical standards}

Conflict of interest The authors M.L., C.Z. and B.M. have conducted their trainings at NEB while all the other authors are employed by NEB, which commercializes SHuffle cells.

Ethical approval This article does not contain any studies with human participants or animals performed by any of the authors.

Open Access This article is licensed under a Creative Commons Attribution 4.0 International License, which permits use, sharing, adaptation, distribution and reproduction in any medium or format, as long as you give appropriate credit to the original author(s) and the source, provide a link to the Creative Commons licence, and indicate if changes were made. The images or other third party material in this article are included in the article's Creative Commons licence, unless indicated otherwise in a credit line to the material. If material is not included in the article's Creative Commons licence and your intended use is not permitted by statutory regulation or exceeds the permitted use, you will need to obtain permission directly from the copyright holder. To view a copy of this licence, visit http://creativecommons.org/licenses/by/4.0/.

\section{References}

Abe R, Jeong HJ, Arakawa D, Dong J, Ohashi H, Kaigome R, Saiki F, Yamane K, Takagi H, Ueda H (2014) Ultra Q-bodies: quench-based antibody probes that utilize dye-dye interactions with enhanced antigen-dependent fluorescence. Sci Rep 4:4640. https://doi.org/ 10.1038/srep04640

Ahmadzadeh M, Farshdari F, Nematollahi L, Behdani M, Mohit E (2020) Anti-HER2 scFv expression in Escherichia coli SHuffle((R))T7 express cells: effects on solubility and biological activity. Mol Biotechnol 62(1):18-30. https://doi.org/10.1007/s12033-01900221-2

Alvarez CL, Corradi G, Lauri N, Marginedas-Freixa I, Leal Denis MF, Enrique N, Mate SM, Milesi V, Ostuni MA, Herlax V, Schwarzbaum PJ (2017) Dynamic regulation of extracellular ATP in Escherichia coli. Biochem J 474(8):1395-1416. https://doi.org/ 10.1042/BCJ20160879

Appenzeller-Herzog C, Ellgaard L (2008) In vivo reduction-oxidation state of protein disulfide isomerase: the two active sites independently occur in the reduced and oxidized forms. Antioxid Redox Signal 10(1):55-64. https://doi.org/10.1089/ars.2007.1837

Baumgarten T, Ytterberg AJ, Zubarev RA, de Gier JW (2018) Optimizing recombinant protein production in the Escherichia coli periplasm alleviates stress. Appl Environ Microbiol 84(12):1-12. https://doi.org/10.1128/AEM.00270-18

Berkmen M (2012) Production of disulfide-bonded proteins in Escherichia coli. Protein Expr Purif 82(1):240-251. https://doi. org/10.1016/j.pep.2011.10.009

Blackshields G, Sievers F, Shi W, Wilm A, Higgins DG (2010) Sequence embedding for fast construction of guide trees for multiple sequence alignment. Algorithms Mol Biol 5:21-32. https://doi.org/10.1186/ 1748-7188-5-21

Boratyn GM, Camacho C, Cooper PS, Coulouris G, Fong A, Ma N, Madden TL, Matten WT, McGinnis SD, Merezhuk Y, Raytselis Y, Sayers EW, Tao T, Ye J, Zaretskaya I (2013) BLAST: a more efficient report with usability improvements. Nucleic Acids Res 41(Web Server issue):W29-33. https://doi.org/10.1093/nar/gkt282

Bosello-Travain V, Conrad M, Cozza G, Negro A, Quartesan S, Rossetto M, Roveri A, Toppo S, Ursini F, Zaccarin M, Maiorino M (2013) Protein disulfide isomerase and glutathione are alternative substrates in the one cys catalytic cycle of glutathione peroxidase 7 . Biochim Biophys Acta 1830(6):3846-3857. https://doi.org/10.1016/j. bbagen.2013.02.017

Eliseev IE, Yudenko AN, Vysochinskaya VV, Svirina AA, Evstratyeva AV, Drozhzhachih MS, Krendeleva EA, Vladimirova AK, Nemankin TA, Ekimova VM, Ulitin AB, Lomovskaya MI, Yakovlev PA, Bukatin AS, Knyazev NA, Moiseenko FV, Chakchir OB (2018) Crystal structures of a llama VHH antibody BCD090-M2 targeting human ErbB3 receptor. F1000Res 7:57. https://doi.org/10.12688/f1000research.13612.2

Feige MJ, Groscurth S, Marcinowski M, Shimizu Y, Kessler H, Hendershot LM, Buchner J (2009) An unfolded CH1 domain controls the assembly and secretion of IgG antibodies. Mol Cell 34(5): 569-579. https://doi.org/10.1016/j.molcel.2009.04.028

Foit L, Morgan GJ, Kern MJ, Steimer LR, von Hacht AA, Titchmarsh J, Warriner SL, Radford SE, Bardwell JC (2009) Optimizing protein stability in vivo. Mol Cell 36(5):861-871. https://doi.org/10.1016/j. molcel.2009.11.022

Gaciarz A, Khatri NK, Velez-Suberbie ML, Saaranen MJ, Uchida Y, Keshavarz-Moore E, Ruddock LW (2017) Efficient soluble expression of disulfide bonded proteins in the cytoplasm of Escherichia coli in fed-batch fermentations on chemically defined minimal media. Microb Cell Factories 16(1):108. https://doi.org/10.1186/ s12934-017-0721-x 
Gupta SK, Shukla P (2017) Microbial platform technology for recombinant antibody fragment production: a review. Crit Rev Microbiol 43(1):31-42. https://doi.org/10.3109/1040841X.2016.1150959

Hong Y, Zeng J, Wang X, Drlica K, Zhao X (2019) Post-stress bacterial cell death mediated by reactive oxygen species. Proc Natl Acad Sci U S A 116(20):10064-10071. https://doi.org/10.1073/pnas. 1901730116

Iuchi Y, Okada F, Tsunoda S, Kibe N, Shirasawa N, Ikawa M, Okabe M, Ikeda Y, Fujii J (2009) Peroxiredoxin 4 knockout results in elevated spermatogenic cell death via oxidative stress. Biochem J 419(1): 149-158. https://doi.org/10.1042/BJ20081526

Karyolaimos A, Ampah-Korsah H, Hillenaar T, Mestre Borras A, Dolata KM, Sievers S, Riedel K, Daniels R, de Gier JW (2019) Enhancing recombinant protein yields in the $E$. coli periplasm by combining signal peptide and production rate screening. Front Microbiol 10: 1511. https://doi.org/10.3389/fmicb.2019.01511

Ke N, Berkmen M (2014) Production of disulfide-bonded proteins in Escherichia coli. Curr Protoc Mol Biol 108:16 1B 1-21 https://doi. org/10.1002/0471142727.mb1601bs108

Laurindo FR, Pescatore LA, Fernandes Dde C (2012) Protein disulfide isomerase in redox cell signaling and homeostasis. Free Radic Biol Med 52(9):1954-1969. https://doi.org/10.1016/j.freeradbiomed. 2012.02.037

Leith EM, O'Dell WB, Ke N, McClung C, Berkmen M, Bergonzo C, Brinson RG, Kelman Z (2019) Characterization of the internal translation initiation region in monoclonal antibodies expressed in Escherichia coli. J Biol Chem 294(48):18046-18056. https://doi. org/10.1074/jbc.RA119.011008

Letunic I, Bork P (2011) Interactive tree of life v2: online annotation and display of phylogenetic trees made easy. Nucleic Acids Res 39(Web Server issue):W475-8 https://doi.org/10.1093/nar/gkr201

Liu C, Kobashigawa Y, Yamauchi S, Toyota Y, Teramoto M, Ikeguchi Y, Fukuda N, Sato T, Sato Y, Kimura H, Morioka H (2019) Preparation of single-chain Fv antibodies in the cytoplasm of Escherichia coli by simplified and systematic chaperone optimization. J Biochem 166(6):455-462. https://doi.org/10.1093/jb/mvz059

Lobstein J, Emrich CA, Jeans C, Faulkner M, Riggs P, Berkmen M (2012) SHuffle, a novel Escherichia coli protein expression strain capable of correctly folding disulfide bonded proteins in its cytoplasm. Microb Cell Factories 11(1):56. https://doi.org/10.1186/ 1475-2859-11-56

Maiorino M, Bosello-Travain V, Cozza G, Miotto G, Roveri A, Toppo S, Zaccarin M, Ursini F (2015) Understanding mammalian glutathione peroxidase 7 in the light of its homologs. Free Radic Biol Med 83: 352-360. https://doi.org/10.1016/j.freeradbiomed.2015.02.017

Manta B, Boyd D, Berkmen M (2019) Disulfide bond formation in the periplasm of Escherichia coli. EcoSal Plus 8(2). https://doi.org/10. 1128/ecosalplus.ESP-0012-2018

Mirzadeh K, Shilling PJ, Elfageih R, Cumming AJ, Cui HL, Rennig M, Norholm MHH, Daley DO (2020) Increased production of periplasmic proteins in Escherichia coli by directed evolution of the translation initiation region. Microb Cell Factories 19(1):85. https://doi. org/10.1186/s12934-020-01339-8

Mori A, Ojima-Kato T, Kojima T, Nakano H (2018) Zipbodyzyme: development of new antibody-enzyme fusion proteins. J Biosci Bioeng 125(6):637-643. https://doi.org/10.1016/j.jbiosc.2017.12. 021

Nguyen VD, Saaranen MJ, Karala AR, Lappi AK, Wang L, Raykhel IB, Alanen HI, Salo KE, Wang CC, Ruddock LW (2011) Two endoplasmic reticulum PDI peroxidases increase the efficiency of the use of peroxide during disulfide bond formation. J Mol Biol 406(3): 503-515. https://doi.org/10.1016/j.jmb.2010.12.039

Petersen TN, Brunak S, von Heijne G, Nielsen H (2011) SignalP 4.0: discriminating signal peptides from transmembrane regions. Nat Methods 8(10):785-786. https://doi.org/10.1038/nmeth.1701
Ramming T, Okumura M, Kanemura S, Baday S, Birk J, Moes S, Spiess M, Jeno P, Berneche S, Inaba K, Appenzeller-Herzog C (2015) A PDI-catalyzed thiol-disulfide switch regulates the production of hydrogen peroxide by human Ero1. Free Radic Biol Med 83:361-372. https://doi.org/10.1016/j.freeradbiomed.2015.02.011

Reddy PT, Brinson RG, Hoopes JT, McClung C, Ke N, Kashi L, Berkmen M, Kelman Z (2018) Platform development for expression and purification of stable isotope labeled monoclonal antibodies in Escherichia coli. MAbs 10(7):992-1002. https://doi.org/10.1080/ 19420862.2018.1496879

Reuter WH, Masuch T, Ke N, Lenon M, Radzinski M, Van Loi V, Ren G, Riggs P, Antelmann H, Reichmann D, Leichert LI, Berkmen M (2019) Utilizing redox-sensitive GFP fusions to detect in vivo redox changes in a genetically engineered prokaryote. Redox Biol 26: 101280. https://doi.org/10.1016/j.redox.2019.101280

Ritz D, Lim J, Reynolds CM, Poole LB, Beckwith J (2001) Conversion of a peroxiredoxin into a disulfide reductase by a triplet repeat expansion. Science 294(5540):158-160

Robinson MP, Ke N, Lobstein J, Peterson C, Szkodny A, Mansell TJ, Tuckey C, Riggs PD, Colussi PA, Noren CJ, Taron CH, DeLisa MP, Berkmen M (2015) Efficient expression of full-length antibodies in the cytoplasm of engineered bacteria. Nat Commun 6:8072-8081. https://doi.org/10.1038/ncomms9072

Sambrook J, Fritsch EF, Maniatis T (1989) Molecular cloning: a laboratory manual. Cold Spring Harbor Laboratory Press

Scheinfeld N (2003) Adalimumab (HUMIRA): a review. J Drugs Dermatol 2(4):375-377

Schlegel S, Lofblom J, Lee C, Hjelm A, Klepsch M, Strous M, Drew D, Slotboom DJ, de Gier JW (2012) Optimizing membrane protein overexpression in the Escherichia coli strain Lemo21(DE3). J Mol Biol 423(4):648-659. https://doi.org/10.1016/j.jmb.2012.07.019

Sievers F, Wilm A, Dineen D, Gibson TJ, Karplus K, Li W, Lopez R, McWilliam H, Remmert M, Soding J, Thompson JD, Higgins DG (2011) Fast, scalable generation of high-quality protein multiple sequence alignments using Clustal Omega. Mol Syst Biol 7:539. https://doi.org/10.1038/msb.2011.75

Simmons LC, Reilly D, Klimowski L, Raju TS, Meng G, Sims P, Hong K, Shields RL, Damico LA, Rancatore P, Yansura DG (2002) Expression of full-length immunoglobulins in Escherichia coli: rapid and efficient production of aglycosylated antibodies. J Immunol Methods 263(1-2):133-147

Spadiut O, Capone S, Krainer F, Glieder A, Herwig C (2014) Microbials for the production of monoclonal antibodies and antibody fragments. Trends Biotechnol 32(1):54-60. https://doi.org/10.1016/j. tibtech.2013.10.002

Sternke M, Tripp KW, Barrick D (2019) Consensus sequence design as a general strategy to create hyperstable, biologically active proteins. Proc Natl Acad Sci U S A 116(23):11275-11284. https://doi.org/10. 1073/pnas. 1816707116

Ta DT, Redeker ES, Billen B, Reekmans G, Sikulu J, Noben JP, Guedens W, Adriaensens P (2015) An efficient protocol towards sitespecifically clickable nanobodies in high yield: cytoplasmic expression in Escherichia coli combined with intein-mediated protein ligation. Protein Eng Des Sel 28(10):351-363. https://doi.org/10. 1093/protein/gzv032

Tavender TJ, Springate JJ, Bulleid NJ (2010) Recycling of peroxiredoxin IV provides a novel pathway for disulphide formation in the endoplasmic reticulum. EMBO J 29(24):4185-4197. https://doi.org/10. 1038/emboj.2010.273

Toppo S, Vanin S, Bosello V, Tosatto SC (2008) Evolutionary and structural insights into the multifaceted glutathione peroxidase (Gpx) superfamily. Antioxid Redox Signal 10(9):1501-1514. https://doi. org/10.1089/ars.2008.2057

Vermeulen JG, Burt F, van Heerden E, Cason E, Meiring M (2018) Evaluation of in vitro refolding vs cold shock expression: production 
of a low yielding single chain variable fragment. Protein Expr Purif 151:62-71. https://doi.org/10.1016/j.pep.2018.06.005

Vitu E, Kim S, Sevier CS, Lutzky O, Heldman N, Bentzur M, Unger T, Yona M, Kaiser CA, Fass D (2010) Oxidative activity of yeast Erolp on protein disulfide isomerase and related oxidoreductases of the endoplasmic reticulum. J Biol Chem 285(24):18155-18165. https://doi.org/10.1074/jbc.M109.064931

Wang L, Zhang L, Niu Y, Sitia R, Wang CC (2014) Glutathione peroxidase 7 utilizes hydrogen peroxide generated by Erol $\alpha$ to promote oxidative protein folding. Antioxid Redox Signal 20(4):545-556. https://doi.org/10.1089/ars.2013.5236

Yamamoto Y, Ritz D, Planson AG, Jonsson TJ, Faulkner MJ, Boyd D, Beckwith J, Poole LB (2008) Mutant AhpC peroxiredoxins suppress thiol-disulfide redox deficiencies and acquire deglutathionylating activity. Mol Cell 29(1):36-45. https://doi.org/10.1016/j.molcel. 2007.11.029

Yusakul G, Sakamoto S, Tanaka H, Morimoto S (2018) Improvement of heavy and light chain assembly by modification of heavy chain constant region $1(\mathrm{CH} 1)$ : application for the construction of an anti-paclitaxel fragment antigen-binding (Fab) antibody. J Biotechnol 288:41-47. https://doi.org/10.1016/j.jbiotec.2018.10. 009

Zarschler K, Witecy S, Kapplusch F, Foerster C, Stephan H (2013) Highyield production of functional soluble single-domain antibodies in the cytoplasm of Escherichia coli. Microb Cell Factories 12:97. https://doi.org/10.1186/1475-2859-12-97

Zhang J, Zhao Y, Cao Y, Yu Z, Wang G, Li Y, Ye X, Li C, Lin X, Song H (2020) Synthetic sRNA-based engineering of Escherichia coli for enhanced production of full-length immunoglobulin G. Biotechnol J 15(5):e1900363. https://doi.org/10.1002/biot.201900363

Publisher's note Springer Nature remains neutral with regard to jurisdictional claims in published maps and institutional affiliations. 